\title{
The intervention of prevention: Is diet the next frontier of interventional cardiology?
}

\author{
Michael Scott Fenster \\ College of Health Professions and Biomedical Sciences, University of Montana, Missoula, Montana, USA
}

\section{What did our Ancestors know?}

Millennia ago, some of the world's very first cookbooks were being written - by physicians. Dietetics was an important and powerful part of the healer's armamentarium against disease. And it remained so until the very recent past; when the post-World War II era ushered in tremendous changes to our food and food pathways; setting the foundation stones of modern agribusiness and the modern food industry.

Over theensuing nearcentury, misperception and misunderstanding has reigned. We were told and taught that it was simply excess calories from fat, and primarily saturated animal fat, that led to obesity, and hypercholesterolemia. This initiated the development of atherosclerosis and ultimately the manifestation of cardiovascular disease in the form of thrombotic acute coronary syndromes and myocardial infarction.

But amongst the confusion, contradictions, and retractions that defined official food guidelines and recommendations; the interest in the power of diet, like many potential areas intervention filed under "lifestyle," fell by the wayside. Especially, when compared to the glamour, glitz and power of immediate gratification delivered by technological innovation. Daily deprivation and suffering are no match for a procedure like PCI and stenting, that have become almost as ubiquitously drive-thru in the United States as fast food itself.

Despite its omnipresence, both physicians and patients alike took solace in the fact that there was solid evidence that strongly supported an aggressive interventional approach in the setting of acute myocardial infarction, both STEMI and non-STEMI. For such presentations there is clear benefit. The leap of faith comes from assuming such benefit naturally extends into other forms of acute coronary syndrome and angina relief. Since the inception of angioplasty, the belief has been that, of course, it would.

For a lot of these patients who currently receive intra-coronary stents, the goal of such a procedure is symptomatic relief of their chest pain or stable angina. However, there is no evidence from blinded, placebo-controlled, randomized trials to show if there is benefit, over and beyond maximal baseline medical therapy, in a procedure that is performed in over 500,000 individuals annually worldwide.

That is, until ORBITA was performed. This was just such a trial of PCI versus a placebo procedure for angina relief that was done at five study sites in the UK. The researchers enrolled 230 patients with ischemic symptoms consistent with stable angina. The patients underwent cardiac catheterization, a common practice to evaluate angina in the United States, and they were included in the study if they had a single coronary artery with a severe ( $\geq 70$ percent) stenosis. This degree of blockage was also measured physiologically with fractional flow reserve (FFR). The mean value in the study was a FFR of 0.69 . All these findings would provide an incontrovertible rationale for the implantation of an intra-coronary stent according to current US guidelines.

Patients either received such a device or underwent a sham procedure. All participants then underwent 6 weeks of medication optimization. Subsequently, they were questioned regarding their symptoms, and they underwent stress testing. There was no significant difference in the degree of chest pain or exercise (treadmill test) time between groups, and no one in either group died.

\section{The researchers concluded that:}

ORBITA has implications for our clinical understanding of stable angina. The concept of a simple linear link between a tight stenosis and angina is attractive to patients, easily explained by physicians, and biologically plausible. Moreover, since relieving the anatomical and haemodynamic features of stenosis by unblinded PCI is followed by the patient reporting angina relief, it is understandable that this link becomes generally accepted.

However, forgetting the potential magnitude of placebo effects prevents exploration of the inevitably complex relationship between anatomy, physiology, and symptoms. Clinicians have hoped there might be a simple entity named ischaemia, which manifests as positive tests and clinical symptoms, and that treatment by PCI would eliminate all these manifestations concordantly. Perhaps this notion is too optimistic [1].

\section{And, I might add, too simplistic. We are complicated.}

And so is our relationship with food. While the fat and saturated fat hypothesis is attractive on the surface for its simplicity; the facts do not support the conclusions.

- The original recommendations (1973 in the US, 1983 in the UK) had no basis in any scientific evidence derived from randomized, controlled clinical trials -the recognized gold standard in such matters. The analysis examining the approval of these guidelines concluded that "The dietary fat guidelines were not supported by RCT [randomized controlled trials] or epidemiological evidence available at the time of their introduction [2]."

Correspondence to: Michael S. Fenster, MD FACC, FSCA\&I, PEMBA, Affiliate Faculty, College of Health Professions and Biomedical Sciences, University of Montana, Missoula, Montana, USA

Received: March 06, 2018; Accepted: March 12, 2018; Published: March 15 , 2018 
- A study which systematically reviewed saturated, not just total, fat had mortality as the end point. They found that "Saturated fats are not associated with all-cause mortality, CVD [cardiovascular disease], CHD [coronary heart disease], ischemic stroke, or type 2 diabetes [3]"

- Another meta-analysis also looked at saturated, not just total fat, with disease as the end point. The researchers concluded that "Metaanalysis of prospective epidemiologic studies showed that there is no significant evidence for concluding that dietary saturated fat is associated with an increased risk of CHD or CVD [4]."

- Yet another group of scientists examined the saturated fat question, concentrating on saturated, not total fat, and its relationship with the risk for CAD. They looked in detail at saturated, monounsaturated, polyunsaturated, and trans-fatty acids (TFAs). They also examined the specific long chain saturated fatty acids, palmitic (C16:0) and margaric (C17:0); because even among classes of fats (like long chain saturated fatty acids), the body is built to utilize many fats uniquely according to their individual characteristics. The conclusion of their analysis was that "Current evidence does not clearly support cardiovascular guidelines that encourage high consumption of polyunsaturated fatty acids and low consumption of total saturated fats [5]."

- A 2009 meta-analysis conducted a systematic review and metaanalysis of randomized controlled trials and prospective cohort studies looking at total and saturated fat and the risk of CHD and mortality. The take-away was that "Intake of total fat was not significantly associated with CHD mortality. Intake of total fat was also unrelated to CHD events [6]."

- The most recent investigation "Finds that the epidemiological evidence currently available does not support the dietary fat guidelines....The conclusion of the four systematic reviews and three meta-analyses is that there was no evidence to support the dietary fat guidelines being introduced and there is no evidence currently available to support them. Not one review has found evidence to support [current] public health dietary fat guidelines [7]."

Yet despite the data, professional organizations like the American College of Cardiology (ACC) and the American Heart Association (AHA) continue promulgate the mythos that dietary redemption lies in the continued avoidance of fat, saturated fat, and cholesterol. What modern nutritional science has clearly demonstrated are the limitations of drawing conclusions about health effects of any food product based on theories about its nutrient contents [8].

What is important is the quality of specific foods and overall diet patterns. So often modern investigation continues to focus on single isolated nutrients, as opposed to foods, in the context of cardiometabolic risk, often at the expense of the larger picture and common sense [9]. Repeatedly focusing on isolated nutrients leads to paradoxical dietary choices and unhelpful industry formulations.

For example, the US National School Lunch Programs in 2012 banned whole milk, but allowed sugar-sweetened chocolate skim milk [10]. This untested intervention in thirty-one million American children was based on hypothesized effects of total calories, total fat, and saturated fat in milk rather than empirical evidence on the health effects of whole versus skim milk. Results that when analyzed objectively show no untoward effect on health from whole milk.

Longitudinal studies suggest no harm from the consumption of whole-fat milk with respect to obesity, diabetes mellitus, or cardiovascular disease in adults [11-14]. Many additional studies suggest that dairy fat may have potential benefits for the prevention and treatment of diabetes mellitus.

Fermented dairy is a prominent constituent of the Mediterraneanbased dietary approach. The Mediterranean diet and its many variations have been shown to improve a range of health-related risk factors, reduce long-term weight gain, and are consistently associated with lower risk of adverse clinical events [15-17]. This, despite the fact that the traditional Mediterranean diet is higher in both sodium and total fat than the standard American diet (SAD). Excellent work regarding healthful outcomes in the Mediterranean dietary approach has been performed by the Prevención con Dieta Mediterránea (PREDIMED) group.

In one of their studies a Mediterranean approach including supplementation with extra virgin olive oil or mixed nuts, combined with lifestyle advice, led to significant reductions in cardiovascular events and the risk of developing diabetes compared to a traditional low-fat diet approach. Of critical import, there was no calorie counting. People on the Mediterranean diet could eat as much as they liked without restriction $[18,19]$. The magnitude of benefit obtained with diet was on par with that seen with stain therapy; a post discharge requirement in the US.

Other research has shown the Mediterranean diet results not only in a lower incidence and prevalence of diseases like diabetes, but less significant complications like strokes associated with such diseases, and in some circumstances reversal of diabetes and related conditions [20]. The Mediterranean diet is associated with a significantly lower risk of developing many of the disabilities and diseases associated with lifelong consumption of the SAD, like Alzheimer's dementia [21].

Such a suboptimal diet is the leading risk factor for death and disability in the United States and worldwide [22,23]. The disability and disease as a result of such poor dietary choices are estimated to cause more than 17.3 trillion dollars of cumulative economic loss between 2011 and 2030 from healthcare expenditures, reduced productivity, and lost capital across the globe [24]. What is universal to any of the healthful approaches to diet examined around the globe, in contradistinction to the $\mathrm{SAD}$, is that like the Mediterranean approach there is a consistent emphasis on fresh, wholesome, and authentic food that is minimally processed. This is what makes it sustainable as "it constitutes a set of skills, knowledge, practices and traditions ranging from the landscape to the table, including the crops, harvesting, fishing, conservation, processing, preparation and, particularly, consumption of food [25]."

An intervention can be defined as: "action taken to improve a situation, especially a medical disorder." Historically, in interventional cardiology, this has been accomplished through the use of devices and drugs. Interventional cardiologists have traditionally taken the lead in treating atherosclerotic CAD; often being seen as the ones to "fix" the problem. But despite the technology, it is not a fix but a patch; albeit an expensive patch of metal, polymer, and drug, but a patch nonetheless.

Many oncology centers around the globe now embrace a robust, diverse, and integrative approach to treating the patient with cancer in an effort to heal rather than simply offer a partial cure for a disease. A cure which without engagement and acceptance by the patient becomes an evanescent illusion.

The time has come for interventional cardiology to search and stand at the helm. Perhaps it is time to go back to the future, back where 
healing started, in the kitchen. Perhaps our next focus of intervention should be one of integration. The intervention of prevention, primary and secondary, starts with what we eat. For as for Jean Anthelme Brillat-Savarin wisely observed centuries ago, "Tell me what you eat, and I will tell you who you are." The interventional cardiologist of the future may add, "and the state of your coronaries."

\section{References}

1. Al-Lamee R, Thompson D, Dehbi HM, Sen S, Tang K, et al. (2017) Percutaneous coronary intervention in stable angina (ORBITA): a double-blind, randomised controlled trial. Lancet 391: 31-40. [Crossref]

2. Harcombe Z, Baker JS, DiNicolantonio JJ, Davies B, Sculthorpe N, et al. (2015) Evidence from randomised controlled trials did not support the introduction of dietary fat guidelines in 1977 and 1983: a systematic review and meta-analysis. Open Heart 3: e000409. [Crossref]

3. de Souza RJ, Mente A, Maroleanu A, Cozma AI, Ha V, et al. (2015) Intake of saturated and trans unsaturated fatty acids and risk of all cause mortality, cardiovascular disease, and type 2 diabetes: systematic review and meta-analysis. BMJ 351: h397. [Crossref]

4. Siri-Tarino PW, Sun Q, Hu F, Krauss RM (2010) Meta-Analysis of Prospective Cohort Studies Evaluating the Association of Saturated Fat with Cardiovascular Disease. Am J Clin Nutr 91: 535-546. [Crossref]

5. Chowdhury R, Warnakula S, Kunutsor S, Crowe F, Ward HA, et al. (2014) Association of dietary, circulating, and supplement fatty acids with coronary risk: a systematic review and meta-analysis. Ann Intern Med 160: 398-406. [Crossref]

6. Skeaff CM, Miller J (2009) Dietary Fat and Coronary Heart Disease: Summary of Evidence from Prospective Cohort and Randomised Controlled Trials. Anal Nutr \& Metab 55: 173-201. [Crossref]

7. Harcombe Z, Baker J, Davies B (2017) Evidence from prospective cohort studies did not support the introduction of dietary fat guidelines in 1977 and 1983: a systematic review. Br J Sports Med 51: 1737-1742. [Crossref]

8. Mozaffarian D, Ludwig DS (2010) Dietary guidelines in the 21st century-a time for food. JAMA 304: 681-682. [Crossref]

9. Jacobs DR Jr, Tapsell LC (2007) Food, not nutrients, is the fundamental unit in nutrition. Nutr Rev 65: 439-450. [Crossref]

10. USDA (2015) 2015 Dietary Guidelines Advisory Committee.

11. Smith JD, Hou T, Ludwig DS, Rimm EB, Willett W, et al. (2015) Changes in intake of protein foods, carbohydrate amount and quality, and long-term weight change: results from 3 prospective cohorts. Am J Clin Nutr 101: 1216-1224. [Crossref]
12. Wang H, Troy LM, Rogers GT, Fox CS, McKeown NM, et al. (2014) Longitudinal association between dairy consumption and changes of body weight and waist circumference: the Framingham Heart Study. Int J Obes 38: 299-305. [Crossref]

13. Sluijs I, Forouhi NG, Beulens JW, van der Schouw YT, Agnoli C, et al. (2012) The amount and type of dairy product intake and incident type 2 diabetes: results from the EPIC-InterAct Study. Am J Clin Nutr 96: 382-390. [Crossref]

14. Drouin-Chartier JP, Côté JA, Labonté MÈ, Brassard D, Tessier-Grenier M, et al. (2016) Comprehensive Review of the Impact of Dairy Foods and Dairy Fat on Cardiometabolic Risk. Adv Nutr 7: 1041-1051. [Crossref]

15. Mozaffarian D, Appel LJ, Van Horn L (2011) Components of a cardioprotective diet new insights. Circulation 123: 2870-2891. [Crossref]

16. Mozaffarian D, Hao T, Rimm EB, Willett WC, Hu FB (2011) Changes in diet and lifestyle and long-term weight gain in women and men. N Engl J Med 364: 2392-2404. [Crossref]

17. Djoussé L, Akinkuolie AO, Wu JH, Ding EL, Gaziano JM (2012) Fish consumption, omega-3 fatty acids and risk of heart failure: a meta-analysis. Clin Nutr 31: 846-853. [Crossref]

18. Estruch R, Ros E, Salas-Salvadó J, Covas MI, Corella D, et al. (2013) Primary prevention of cardiovascular disease with a Mediterranean diet. $N$ Engl J Med 368 : 1279-1290. [Crossref]

19. Martínez-González MA, Salas-Salvadó J, Estruch R, Corella D, Fitó M, et al. (2015) Benefits of the Mediterranean Diet: Insights From the PREDIMED Study. Prog Cardiovasc Dis 58: 50-60. [Crossref]

20. Corella D, Carrasco P, Sorlí JV, Estruch R, Rico-Sanz J, et al. (2013) Mediterranean Diet Reduces the Adverse Effect of the TCF7L2-rs7903146 Polymorphism on Cardiovascular Risk Factors and Stroke Incidence: A randomized controlled trial in a high-cardiovascular-risk population. Diabetes Care 36: 3803-3811. [Crossref]

21. Fenster MS (2015) 10 Healthy Foods that Protect Your Brain.

22. Lim SS, Vos T, Flaxman AD, Shibuya K, Adair-Rohani H, et al. (2012) A comparative risk assessment of burden of disease and injury attributable to 67 risk factors and risk factor clusters in 21 regions, 1990-2010: a systematic analysis for the Global Burden of Disease Study 2010. Lancet 380: 2224-2260. [Crossref]

23. Murray CJ, Atkinson C, Bhalla K, Birbeck G, Burstein R, et al. (2013) The state of US health, 1990-2010: burden of diseases, injuries, and risk factors. JAMA 310: 591-608. [Crossref]

24. Bloom D, Cafiero E, Jané-Llopis E (2011) The Global Economic Burden of Noncommunicable Diseases. Geneva, Switzerland: World Economic Forum.

25. Food and agricultural organization of the United Nations. (2014) Agriculture and Consumer Protection Department.

Copyright: (C2018 Fenster MS. This is an open-access article distributed under the terms of the Creative Commons Attribution License, which permits unrestricted use, distribution, and reproduction in any medium, provided the original author and source are credited. 